\title{
Cytoskeletal proteins in cortical development and disease: actin associated proteins in periventricular heterotopia
}

\section{OPEN ACCESS}

Edited by:

Takeshi Kawauchi,

Keio University School of Medicine/PRESTO, JST, Japan

Reviewed by:

Makoto Sato,

Osaka University, Japan Zhiheng Xu,

Institute of Genetics and Developmental Biology, China

*Correspondence: Volney L. Sheen,

Department of Neurology, Beth Israel Deaconess Medical Center and Harvard Medical School, 3 Blackfan Circle, CLS-628H, Boston, MA 02115, USA

vsheen@bidmc.harvard.edu

Received: 01 December 2014 Accepted: 07 March 2015

Published: 01 April 2015

Citation:

Lian G and Sheen VL (2015)

Cytoskeletal proteins in cortical development and disease: actin associated proteins in periventricular heterotopia.

Front. Cell. Neurosci. 9:99. doi: 10.3389/fncel.2015.00099

\author{
Gewei Lian and Volney L. Sheen * \\ Department of Neurology, Beth Israel Deaconess Medical Center and Harvard Medical School, Boston, MA, USA
}

The actin cytoskeleton regulates many important cellular processes in the brain, including cell division and proliferation, migration, and cytokinesis and differentiation. These developmental processes can be regulated through actin dependent vesicle and organelle movement, cell signaling, and the establishment and maintenance of cell junctions and cell shape. Many of these processes are mediated by extensive and intimate interactions of actin with cellular membranes and proteins. Disruption in the actin cytoskeleton in the brain gives rise to periventricular heterotopia $(\mathrm{PH}), \mathrm{a}$ malformation of cortical development, characterized by abnormal neurons clustered deep in the brain along the lateral ventricles. This disorder can give rise to seizures, dyslexia and psychiatric disturbances. Anatomically, $\mathrm{PH}$ is characterized by a smaller brain (impaired proliferation), heterotopia (impaired initial migration) and disruption along the neuroependymal lining (impaired cell-cell adhesion). Genes causal for PH have also been implicated in actin-dependent processes. The current review provides mechanistic insight into actin cytoskeletal regulation of cortical development in the context of this malformation of cortical development.

Keywords: filamin, formin, RhoGTPases, actin cytoskeleton, proliferation, polarity, migration, periventricular heterotopia

\section{Introduction}

The cerebral cortex originates from an expansion of neural tube, which consists of a singlecell-layered, pseudostratified neuroepithelial cells (neural stem cells; Götz and Huttner, 2005). Neuroepithelial cells extend their processes from the apical side (ventricular zone) to the basal lamina, and undergo interkinetic nuclear migration along the apical-basal axis throughout the cell cycle. The nuclei locate to the basal lamina during G1 phase, staying at the basal lamina during S phase, and transition back to the apical side during G2 phase. Mitosis of most neural stem cells occurs at the apical surface, where adhesion proteins like $\mathrm{N}$-cadherin and cytoskeleton-associated proteins form dense and dynamic adhesion structures. As neuroepithelial cells divide, neural cells adopt different cell fate specification-one proliferating neural stem cells and another differentiating neuronal cells by symmetric and asymmetric divisions (Cremisi et al., 2003). At an early stage of mouse corticogenesis, the neuroepithelial cells mainly adopt symmetric cell divisions to expand the neuroepithelial plane, thereby promoting enlargement the ventricle surface. As development progresses, the neuroepithelial cells begin to be progressively biased toward 
asymmetric division to generate one self-renewed progenitor and another differentiating intermediate progenitors (basal progenitors) or post-mitotic neurons. The post-mitotic neurons attach and migrate along radial glial scaffolds out of the expanding ventricular zone (germinal zone) creating a new overlying layer of cells called the preplate. The laminar position of neurons is characteristic of their birthdate, such that younger neuroblasts migrate past their older counterparts to form the more superficial layers of the cortex. Finally, once neurons reach their cortical destinations, they differentiate and adopt the complex dendritic and axonal connections that are characteristic of fully mature cortical neurons (Ohnuma and Harris, 2003). At later stages, neurogenesis declines and astroglial differentiation begins.

While different actin cytoskeletal mechanisms are often independently implicated in regulation of neural proliferation, migration and differentiation (Duong et al., 1994; Schaar and McConnell, 2005; Munro, 2006; Witte and Bradke, 2008; Solecki et al., 2009; Moon and Wynshaw-Boris, 2013), a primary role for the actin cytoskeleton in facilitating crosstalk between various cell membrane and intracellular molecules would suggest that shared actin dependent pathways could mediate these developmental processes. For example, cell fate specification of neural stem cells along the neuroependymal lining depends upon the actin cytoskeleton to direct cytokinesis and localization of cell fate determining proteins. This actin dependent process dictates whether progenitors produce daughter progeny capable of self-renewal or postmitotic neurons (Knoblich, 2008). Under a constant rate of cell cycle, the greater the number of progenitors that undergo self-renewal, the larger the number of neural progenitors generated, giving rise to more postmitotic neurons and leading to bigger brain size. Conversely, increased differentiation will lead to a fewer neural progenitors over time, and ultimately fewer neurons and smaller brain size. In this respect, a shared actin cytoskeletal dependent pathway regulates both neural proliferation and differentiation, thereby maintaining a delicate tune of self-renewal vs. differentiation to direct formation of the cerebral cortex. Within this same framework, the same actin cytoskeletal pathways that regulate cell fate specification will also mediate neuronal migration, as intermediate progenitors and post-mitotic neurons will migrate toward the intermediate zone or cortical plate respectively, whereas progenitors remain restricted to the ventricular zone. In this review, we focus on a fundamental actin cytoskeletal pathway that singularly directs each of these developmental stages during corticogenesis.

\section{Actin Cytoskeletal-Associated Proteins}

The majority of actin cytoskeletal-associated proteins participate in the formation of actin filaments by regulating the dynamic processes of actin polymerization and de-polymerization. Actin polymerization occurs under the effect of actin-nucleating proteins, including Arp2/3 and formin proteins. The Arp2/3 complex nucleates G-actin in the lamellipodia to form short, branched actin filaments, whereas formins nucleate actin polymerization into long, unbranched filaments, which are important for both stress fiber formation and contractile ring assembly in mitosis (Bovellan et al., 2014; Fried et al., 2014; Khaitlina, 2014; Pan et al., 2014; Zhang et al., 2015). In addition, the actin polymerization state is also regulated by many small GTP-binding proteins like Rho GTPases, which cycle between active and inactive states through GTP to GDP exchange (Ciobanasu et al., 2013; Chen and Friml, 2014; Murali and Rajalingam, 2014). Actin polymerization coincides with a homeostatic de-polymerization of actin filaments through actinsevering molecules like cofilin and gelsolin, which bind and dissociate G-actin-GDP from actin filaments (Nag et al., 2013; Hild et al., 2014). Finally, the stability and contractile state of the actin cytoskeleton are regulated by many actin-crosslinking proteins, like filamins, actinin and myosin (Otey and Carpen, 2004; Ma and Adelstein, 2014; Modarres and Mofradt, 2014). Cooperative interaction between these various cytoskeletalassociated proteins can subserve multiple fundamental cell functions.

As F-actin-binding proteins, filamins are highly conserved and expressed in all eukaryotic cells. Filamins can crosslink actin filaments into orthogonal networks in the cellular cortical cytoplasm and participate in the anchoring of membrane proteins to the actin cytoskeleton (Gorlin et al., 1990). They also cross-link parallel stress fibers, thereby forming an aligned array in fibroblasts. Structurally, filamins are composed of a tandem calponin-homology $(\mathrm{CH})$ actin-binding domain $(\mathrm{ABD})$ at the $\mathrm{N}$-terminus, 24 immunoglobulin-like repeat domains and a C-terminal dimerization domain. In vertebrates, filamins consist of three isoforms (FlnA, FlnB and FlnC) with molecular weights of $\sim 280 \mathrm{kDa}$ (Nakamura et al., 2011; Razinia et al., 2012). The FLNA gene is located on human chromosome X q28 and mouse chromosome X q37.89, encoding an approximate 2640-amino acid protein. FlnA is ubiquitously expressed in almost all the tissues, especially in developing brain. The FLNB gene resides on human chromosome 3 and mouse chromosome 14 and its encoded protein is predominantly expressed in bone, whereas FLNC is found in muscle tissue. Although FlnB and FlnC are expressed in the brain, they have not been clearly associated with neurological disorders (Sheen et al., 2002; Krakow et al., 2004; Okumura et al., 2013). FlnA, as a scaffolding protein, can interact with more than 45 proteins, including cell adhesion proteins (i.e., integrin) and cell cycle regulators. Recently, FlnA was found to be essential for formation of the E-cadherin-catenin adhesion complex (Feng et al., 2006; Ferland et al., 2009). FlnA also plays important roles in embryonic development by linking these important adhesion proteins and membrane receptors to the actin cytoskeleton. FlnA loss causes various tissue defects during embryonic development, including periventricular heterotopia $(\mathrm{PH})$, skeletal malformation, disorders in vascular and cardiac development and intestinal defect (Fox et al., 1998; Sheen et al., 2001; Robertson et al., 2003). Missense mutations in FLNA gene, which are thought to lead to gain of function, are also associated with various human diseases, such as otopalatodigital syndrome, Melnick-Needles syndrome, thrombocytopenia, and intestinal pseudo-obstruction (Robertson et al., 2003). These roles for filamins in embryonic development are likely to be closely related to their functional mechanisms on diverse 
cellular processes in different types of cells, such as cell receptor signaling, endocytosis and exocytosis of membrane proteins through vesicle trafficking, and signaling transduction in the nucleus.

Formin(s) are members of a family of actin-nucleating, cytoskeletal-associated proteins, which stimulate actin nucleation at the barbed ends of actin to form linear filaments (Basu and Chang, 2007). The mammalian genome encodes more than 10 distinct formin proteins, such as mDia1-3, Daam1/2, and formin $1 / 2$. All the formin family of proteins includes two common domains, the formin homology 1 and 2 domains (FH1 and $\mathrm{FH} 2$ ). The FH1 domain contains a proline-rich sequence motif that can bind profilin and interact with certain proteins containing SRC Homology 3 (SH3) and WW domains. The WW domains are so named because of the presence of two conserved tryptophans (W) which are spaced 20-22 amino acids apart within the sequence (Bork and Sudol, 1994). Profilinassociated actin can be concentrated at the positive ends of actin filaments, and act as the major source of actin used for filament polymerization. The $\mathrm{FH} 2$ domain contains the actin-nucleating domain that can be associated with the fast-growing barbed end of actin filament and increase the actin polymerization rate by binding profilin/actin via its adjoining $\mathrm{FH} 1$ domains. The $\mathrm{FH} 2$ domain forms a ring-shaped dimer, which binds to the positive end of nascent actin filament and recruits two actin monomers for nucleation (Otomo et al., 2005). Flanking the FH1 and FH2 domains, the N-terminal GTPase-binding domain (GBD) and C-terminal autoregulatory domain (DAD) are also present in some subsets of formin proteins, and are important for formin activation (Gould et al., 2011). The binding of Rho GTPases to GBD is thought to open the DAD association with $\mathrm{N}$-terminal autoinhibitory domain (DID), thereby changing the FH2 conformation and facilitating actin binding and polymerization. Except for the conserved FH2 domain, different subsets of formins display a distinct difference in other domain structures, which may endow formins with the capacity responding to varied sorts of cellular signals (Schönichen and Geyer, 2010). mDia 1-3 (Diaph1-3) genes are located in different genomic chromosomes, encode three 1100-1200 aa formin proteins carrying N-terminal GBD and DID domains, and C-terminal $\mathrm{DAD}$ domain. Loss of mDia proteins has been shown to disrupt apical adherens junctions, impact neuroepithelial polarity, and cause periventricular dysplasia in mouse and microcephaly in humans (Thumkeo et al., 2011). The formin 1 (Fmn 1 ) gene is located in mouse chromosome 2 and encodes a 1466-aa protein. It is predominantly expressed in the brain, kidney and developing limb buds, implying a potential role in development of various systems. The formin 2 (Fmn2) gene is located on mouse chromosome 1 and encodes a 1578 aa protein. It is expressed in the central nervous system and developing mesenchyme, suggesting Fmn1 and Fmn2 may share some similar or common functions. Unlike the $\mathrm{mDia}$ proteins, it is not known whether Fmn1/2 contains GBD and DID domains. Collectively, expression of the formin genes in nervous system suggests that they may play diverse roles in neural cell adhesion, migration, proliferation and differentiation.
RhoGTPases are small GTP-binding proteins, the most commonly studied being RhoA, Rac and Cdc42 (Cook et al., 2014). They regulate many cell behaviors like polarity, adhesion, cell division and migration primarily by mediating actin cytoskeletal dynamics. Their regulation of actin polymerization is dependent on both Arp2/3- and formin1/2-nucleating processes. As master regulators of the cytoskeleton, RhoGTPases function between active and inactive states by exchanging GDP with GTP. The switch between activity states is modulated by three classes of regulatory proteins, referred to as guanine nucleotide exchange factors (RhoGEFs), GTPase activating proteins (RhoGAPs), and guanine nucleotide dissociation inhibitors (RhoGDIs). Although RhoA, Rac and $\mathrm{Cdc} 42$ all regulate actin remodeling and polymerization, they have distinctly different effects on actin reorganization through their respective downstream effectors. RhoA modulates actin polymerization, stress fiber assembly and focal adhesion formation through formins, Rock and myosin. Rac regulates actin filament polymerization through Arp $2 / 3$ and WAVE/WASP to produce lamellipodia and membrane ruffles at the leading edge. Cdc42 stimulates filament assembly and filopodia formation via WASP, Arp2/3 and formin. Collectively, RhoGTPases are expressed in neural cells during development of cerebral cortex, regulate downstream actin effectors (formins and Arps), and play pivotal roles in various neural cell developmental functions.

Periventricular Heterotopia is a malformation of cortical development, characterized by nodules of neurons ectopically located along the lateral ventricles. This disorder is thought to reflect impairments along several states of cortical development, including loss in neuroepithelial integrity, disrupted neural proliferation and cell fate specification, and impaired initial neural migration (Sheen, 2012). Mutations in the FLNA gene cause PH (Fox et al., 1998; Sheen et al., 2005). Filamins bind multiple cytoplasmic and cell surface receptors and molecules. Our work shows that filamins also bind formins and RhoGTPases, both of which have been implicated in some kinds of heterotopia formation (Thumkeo et al., 2011; Cappello, 2013). This trimeric complex provides a basic mechanism for modulation of broad actin cytoskeletal dependent processes, essential for cortical development and disease. Given the broad topic of cytoskeletal proteins in brain development, the current review focuses on filamin-associated proteins in corticogenesis, followed by their potential roles in causing $\mathrm{PH}$.

\section{The Actin Cytoskeleton and Neuroepithelial Integrity}

The neuroepithelium forms tight cell -cell or -matrix adhesion junctions at the apical surface of the cortical ventricle. The actin cytoskeleton is also assembled into dense actin cables along the apical surface and anchored onto these adhesion sites through cytoskeletal-associated proteins, such as filamin, formin and catenins. The apical lining is enriched for cytoskeletal proteins and actin filaments play determinant roles on the stability of adhesion junctions, as well as the polarity and integrity of the neuroepithelium. FlnA has been found to be essential for formation of the E-cadherin-catenin adhesion 
complex and its loss causes aberrant adherens junctions in multiple tissues (Feng et al., 2006; Ferland et al., 2009). Furthermore, FlnA-deficient neural progenitors exhibit poor adhesion to extracellular matrix proteins such as laminin. MDial and $\mathrm{mDia} 3$ formin proteins are also both expressed in the developing brain, and mDia3 is especially concentrated at the apical surface of the neuroepithelium. Loss of mDial and mDia3 impairs neuroepithelial cell polarity with attenuated apical actin belts and impaired apical adherens junctions (Thumkeo et al., 2011). Similar to the above findings, $\beta$-catenin is a cytoskeleton-associated protein, linking cadherin(s) to actin filament. Mice with conditional loss of $\beta$-catenin show several abnormalities in the neuroepithelium, including loss of adherens junctions, and impairment of radial migration of neurons toward the superficial layers (Machon et al., 2003). Finally, RhoGTPases such as RhoA and Cdc42 are highly expressed in neuroepithelium and essential for assembly and stability of apical actin cables. Conditional loss of RhoA and Cdc42 in central nervous system impairs apical localization of cadherin, apical accumulation of actin filament and cell-cell junctions. Collectively, these observations raise the possibility of a fundamental filamin-RhoGTPase-formin pathway in maintaining the location and function of adhesions molecules such as cadherins, which are required to ensure neuroependymal integrity.

\section{The Actin Cytoskeleton and Neural Progenitor Proliferation}

Cytoskeletal-associated proteins may not regulate only the stability of cell-cell or cell-extracellular matrix adherens junctions, but also mediate cell proliferation by affecting cell cycle progression (Olson et al., 1995; Cappello et al., 2006; Woodhead et al., 2006; Katayama et al., 2011; Lian et al., 2012; Ercan-Sencicek et al., 2015). For example, actin regulates $M$ (mitosis) phase progression, as the filaments are essential for cleavage furrow formation and completion of cytokinesis (Heng and Koh, 2010). Disruption of actin filaments by inhibitory agents such as latrunculin leads to cytokinesis failure due to a defect in the F-actin cable ring at the cleavage furrow (Lee and Song, 2007). FlnA shows strong expression in the cleavage furrow during mitosis. Additionally, functional loss of actin inhibits centrosome separation early in mitosis and leads to a delay in chromosome segregation late in mitosis (Rosenblatt et al., 2004; Cao et al., 2010). Finally, recent reports have suggested that the interaction of the cortical actin network with astral microtubules is crucial in establishing correct spindle orientation and in proper chromosome segregation in mammalian cells (Théry et al., 2005).

Prior to mitosis, G2-M phase entry requires remodeling of the actin cytoskeleton to change cell shape from an extended to a rounded morphology with cell retraction (Maddox and Burridge, 2003; Cao et al., 2010; Heng and Koh, 2010).This change in cell morphology initially requires activation of RhoA, which triggers a signaling cascade through formin and Rock to re-organize the actin cytoskeleton. Additionally, the cyclin dependent kinase
1 (Cdk1) promotes G2-M transition, and activated Cdk1 phosphorylates Rho GTPase activating protein (p190RhoGAP), down regulating p190RhoGAP hydrolysis of Rho-GTP and thereby promoting RhoA function (Maddox and Burridge, 2003). Our recent study shows that FlnA also regulates Cdk1 activity through Cdk1 phosphorylation and cyclin B degradation (Lian et al., 2012). Lastly, FlnA regulates RhoA activity through mediating p190RhoGAP accumulation in lipid rafts (Mammoto et al., 2007). Therefore, a potential signaling pathway underlying rearrangement of the actin filaments in G2-M phase involves a cascade beginning with FlnA, Cdk1, and p190RhoGAP, which then collectively mediate RhoA and formin/Rock function. This signaling pathway may also be crucial for cell cycle progression through $\mathrm{M}$ phase. Loss of Fln A impairs degradation of cyclin B1-related proteins, thereby delaying the onset and progression through mitosis (Lian et al., 2012). Furthermore, loss of FlnA increases the inhibitory phosphorylation of Cdk1 via its interaction with the kinase Wee1. In developing cerebral cortex, FlnA loss causes a decrease in proliferation rate of neural progenitors and a decline in neural progenitor pool size (Lian et al., 2012). This prolongation in cell cycle would relate to the impairment in actin filament rearrangement. Our understanding of the formin role in cell division is more limited, but insight can be gained from our understanding of formin function in other organ systems. Apart from a known interaction with filamins, Fmn1-deficient mice exhibit a reduction in digit number as well as the absence of a fibula due a defect in chondrocyte proliferation (Zhou et al., 2009). Fmn1 loss is linked to up-regulation of BMP and Msx1 but down-regulation of Fgf4 signals within the apical ectodermal ridge, which may influence mitosis. Finally, other RhoGTPase-related proteins also influence $\mathrm{M}$ phase progression. Both constitutively active and dominant negative Cdc42 inhibit cytokinesis (Drechsel et al., 1997), and loss of its downstream effector mDia3 causes chromosome misalignment during metaphase (Yasuda et al., 2004). Expression of dominant negative Rac1 retards adventricular nuclear migration, and promotes cytokinesis failures (Michaelson et al., 2008; Minobe et al., 2009).

The actin cytoskeleton mediates G1 phase progression after completion of mitosis. Disruption of actin polymerization by the cytochalasin D causes G1 phase arrest (Bohmer et al., 1996; Lian et al., 2012). The cytoskeletal-dependent effects on G1 progression is mediated through cyclin expression and cyclindependent kinase (Cdk) activation. More specifically, the actin cytoskeleton is required for anchorage-dependent expression of cyclin D1, activation of Cdk4/6, phosphorylation of the retinoblastoma protein and transition of G1 phase in nontransformed primary cells. In addition to this primary pathway, cytoskeletal-associated proteins regulate G1 phase progression through other secondary mechanisms. Inhibition of $\mathrm{Cdc} 42$, Racl and RhoA block G1 phase transition and serum-induced DNA synthesis (Olson et al., 1995; Leone et al., 2010). Active RhoA increases the expression of Skp2 protein, which promotes ubiquitinylation-dependent degradation of the Cdk inhibitor p27 kip1 (Mammoto et al., 2004). Conversely, RhoA inactivation results in higher levels of $\mathrm{p}^{\mathrm{kip} 1}$, thereby arresting cell cycle in G1 phase. RhoA inactivation or F-actin disruption are also 
shown to slow down the degradation of another Cdk inhibitor p21 Waf/Cip1 (Coleman et al., 2006). With respect to filamins, our prior study suggests that FlnA also regulates neural progenitor proliferation in G1 phase (Lian et al., 2012) and directs cadherincatenin complex formation. $\beta$-catenin is known to mediate G1 phase progression and neural proliferation, and tethers cadherin to the actin cytoskeleton (Woodhead et al., 2006). Conditional deletion of $\beta$-catenin in developing mouse brain results in a dramatic defect in neural progenitor proliferation and severe brain malformation. In contrast, overexpression of a stabilized $\beta$-catenin causes a significant increase in neural progenitor number and massive expansion of the cerebral cortex (Chenn and Walsh, 2002). Similar to filamins, formins may play coordinative effects on cell proliferation through G1 phase. Our ongoing studies suggest that loss of filamin and formin can affect $\beta$-catenin translocation and cyclin $\mathrm{D}$ expression. Compared to loss of FlnB or Fmn1 alone, loss of both Fmn1 and FlnB in mice leads to a more severe reduction in body size, weight and growth plate length (Hu et al., 2014). These findings would suggest that these actin associated proteins can mediate cell proliferation in multiple organ systems.

From the discussion above, the filamin-formin-RhoGTPase pathway can potentially be implicated in several phases of the cell cycle through interactions with various cell cycle associated proteins. A prevailing role for these proteins in regulation of actin dependent vesicle trafficking would provide a common mechanism for the transport and degradation cell cycle and cell fate proteins, which oversee neural proliferation.

\section{The Actin Cytoskeleton and Cell Polarity and Fate Specification}

The neuroepithelium comprises a distinctive epithelial structure with apical-basal polarity. The actin cytoskeleton is selectively concentrated at the apical side along the ventricle of the developing cerebral cortex, forming a dense and dynamic filament belt to support tight adhesive junctions, cilium stability, and cell polarity, and to maintain a membrane barrier. Acting as regulators of cell shape and binding-partners for polarity proteins, the actin filament and its associated proteins are of key importance for regulating cell polarity (Ohno, 2001; Sawin, 2002; Etienne-Manneville, 2004; Witte and Bradke, 2008; Wang et al., 2009; Gonzalez-Billault et al., 2012). As an example, Rho-GTPases like RhoA, Cdc42 and Racl regulate actin cytoskeleton remodeling, focal adhesion formation and cell polarity (Etienne-Manneville, 2004; Iden and Collard, 2008; Gonzalez-Billault et al., 2012). Activated Cdc42 forms a stable hetero-tetrameric complex with polarizing proteins Par3, Par6, and atypical protein kinase $\mathrm{C}(\mathrm{PKC} \zeta)$ and recruits these molecules to the leading edge to guide the reorientation of the microtubule and centrosome (Ohno, 2001; EtienneManneville, 2004). Cdc42-deficient neural progenitors exhibit multiple apical polarity-related defects including disorientation of cell division, aberrant location of the Par complex and adherens junctions, and severe impairments in the extension of nestin-positive radial fibers (Chen et al., 2006; Peng et al., 2013). Further, Cdc42 loss also causes PH and holoprosencephaly.
As effectors of Rho-GTPases, formins and non-muscle myosin II have been shown to be indispensable for cell polarity (Habas et al., 2001; Ma et al., 2007). Depletion of the formin homologous protein Daaml prevents $\mathrm{Wnt} / \mathrm{Fz}$ activation of Rho and planar cell polarity during Xenopus gastrulation. Ablation of non-muscle myosin II-B in mice results in loss of neuroepithelial adhesion and severe hydrocephalus. Upstream of Rho GTPases, the association of FlnA with Wnt co-receptor Ror2 is required for Wnt5a-induced JNK activation, appropriate orientation of the microtubule organizing center and cell polarity (Nomachi et al., 2008). Further, loss of FlnA leads to a transition from bipolar neuron to multipolar neuron, suggesting a FlnA effect on neuronal polarity (Nagano et al., 2004). Given their physical interaction, filamins and RhoGTPases might regulate formin dependent polarized actin nucleation. Polarized actin provides a mechanism for establishment of neuroepithelial polarity.

Cytoskeletal proteins regulate cell proliferation not only by affecting cell cycle progression, but also through their control over cell fate specification (Chenn and Walsh, 2002; Taverna et al., 2014). During neuroepithelial cell fate specification, neural stem cells must undergo a decision process to undergo self-renewal or differentiate into intermediate progenitors or neurons. This process is dependent upon the asymmetric inheritance of cell fate determining proteins, which is regulated by polarized actin, actin dependent trafficking and degradation of cell fate proteins. In this respect cytoskeletal proteins could indirectly mediate cell fate. Cell fate determinants like Par3, aPKC, and numb as well as stem cell niche molecules like integrin and cadherin all directly or indirectly interact with the actin cytoskeleton, such that cell fate is influenced by cytoskeletal dynamics (Guo et al., 1996; Barros et al., 2003; Cappello et al., 2006; Woodhead et al., 2006). Furthermore, conditional deletion of $\mathrm{Cdc} 42$ at different stages of neurogenesis in mouse telencephalon results in an immediate increase in basal mitoses and altered differentiation of neural progenitors. In mesenchymal cells, loss of p190RhoGAP, which inactivates RhoA activity through GTP hydrolysis, causes a concomitant up-regulation of RhoA activity and increase in myogenic differentiation (but decrease in adipogenesis) (Sordella et al., 2003). In conditional RhoA-deleted embryos, RhoA-deficient neural progenitor cells exhibit accelerated proliferation and reduction in cell-cycle exit, indicating a change in cell fate specification (Katayama et al., 2011). Prior studies have shown that FlnA can bind to RhoA and integrin. Some of our initial observations suggest that loss of FlnA impairs cell cycle exit, in part through disruption of spindle orientation of neural progenitors during mitosis. Moreover, FlnA interactions with formins which nucleate actin in a polarized fashion would provide a basis for asymmetric delivery and localization of cell fate determining proteins.

\section{The Actin Cytoskeleton and Neural Migration}

Cell migration is a highly dynamic process involving cell adhesion, extension, protrusion of filopodia and lamellipodia 
at leading edge and formation of contractile structure at rear edge. All the events require the dynamic remodeling of actin cytoskeleton (Rottner and Stradal, 2011). A variety of literatures have reported that actin cytoskeleton and its associated proteins are essential for cell migration (Fox and Walsh, 1999; Ridley et al., 2003; Raftopoulou and Hall, 2004; Govek et al., 2005; Broussard et al., 2008). For instance, disruption of actin filaments with drug cytochalasin $\mathrm{C}$ in migrating cerebellar granule cells can completely block cell migration (Rivas and Hatten, 1995). Further, melanocytes lacking FLNA show defects in filopodia formation and abnormal surface blebbing, implying a necessary role for FLNA in promoting the assembly of the cortical actin network. Several types of FLNA-deficient cells like macrophages, melanocytes and Dictyostelium amoebae cells display profound defects in motility and chemotaxis (Cunningham et al., 1992; Cox et al., 1996). In contrast, re-expression of FLNA in the cells can rescue each of these phenotypes, further establishing the essential effects of FLNA on migration. FLNA also is concentrated at rear edge of migrating leukocytes, implying FLNA may execute some important functions on rear edge retraction via FLNA-crosslink-driven force (Ohta et al., 2006). Notably, recent studies using transgenetic FlnA-deficient mouse model result in some contradictory conclusions to FLNA effects on neural cell migration (Fox et al., 1998; Feng et al., 2006; Hart et al., 2006). FlnA loss does not affect in vivo migration of neural crest cells into neural-crest-derived tissues like endocardial cushion, and the membrane ruffling, locomotion and migration of in vitro cultured fibroblast cells also appear normal. However, BrdU pulse labeling in embryonic day 15 null FlnA brains shows that the migration of $\mathrm{BrdU}^{+}$cells into the cortical plate is slower than that of age matched wild type cells. Most $\mathrm{BrdU}^{+}$cells from null FlnA cerebral cortices migrate into intermediate zone, but not into the cortical plate, as seen in their wild type littermates by 3 days post-labeling (Zhang et al., 2013). Further, cultured neural progenitor cells from E13 FlnA-null cerebral cortex also show poor spreading on laminin-coated coverslips, implying impairment in cell adhesion on extracellular matrix (Zhang et al., 2013). Finally, FlnA regulates the stability and turnover of adhesion and migratory associated proteins such as paxillin (Zhang et al., 2012, 2013). These migratory defects may in part be related to FlnA interactions with Filip, which regulates the degradation of the actin binding protein and thereby influences neural migration and cell specification (Nagano et al., 2002, 2004). These findings would suggest that filamins may regulate neural motility but do not completely abolish the capacity of progenitors to migrate to their intended site. Thus, these cytoskeletal associated proteins may not form the primary mechanism required to allow cells to migrate, but rather mediate processes (i.e., trafficking of particular receptors/molecules) that influence the rate at which neural progenitors move.

RhoGTPases such as RhoA, Racl and Cdc42 regulate remodeling of actin cytoskeleton, thereby serving as key regulators for cell morphology and migration (Raftopoulou and Hall, 2004). Their effects on neural migration have been extensively studied. Basically, Cdc42 and Racl stimulate formation of filopodia and lamellipodia (Yang et al., 2012), to direct neurite outgrowth and promote neural cell migration
(Chen et al., 2007), whereas RhoA promotes retraction of rear edge and nuclear translocation of neural cell but impairs neurite extension. Other small GTP-binding proteins such as Rnd 2 and Rnd 3 have also been implicated in neural migration, although their relationship with filamins and formins is not known (Heng et al., 2008; Azzarelli et al., 2014). As downstream effectors of Rho GTPases, formins play potential important roles in polymerization and remodeling of actin filament. For instance, mDia deficiency impairs tangential migration of cortical and olfactory inhibitory interneurons (Shinohara et al., 2012). mDia-deficient neuroblasts exhibit reduced separation of the centrosome from the nucleus, retard nuclear translocation and concomitantly impair F-actin movement and condensation at the cellular rear. In non-neural cells, $\mathrm{mDia} 1$ has been shown to regulate formation of stable actin filaments and turnover of focal adhesions. mDia1 deletion impairs focal contacts, and decreases lamellipodial thickness in migrating cells (Yamana et al., 2006). Other formins like Fmn1 and FLR also are shown to function in cellular migration (Zhou et al., 2009; Hu et al., 2014). Fmn1 protein is more similar in sequence to dishevelledassociated activator of morphogenesis-1 (Daam1). Mutations in mouse Fmn1 gene result in limb deformities and incompletely penetrant renal aplasia, and display altered cell protrusion at the leading edge, defective cell spreading, and less focal adhesions. Our recent findings show that formin(s) can physically interact with filamin(s) and they co-express in developing bone and brain tissues (Hu et al., 2014). Loss of both formin and filamin results in serve defects in cell proliferation and migration in developing mouse thoracic wall and brain, suggesting that filamin and formin play cooperative roles in cell proliferation and migration.

Cell migration is a complex and cooperative process with protrusion at cell leading edge and with concomitant retraction at rear edge. The molecular mechanisms underlying neural migration may include some signaling pathways from $G$ proteincoupled receptors, tyrosine-kinase receptors, PI3K, MAPK and Rho GTPases and cytoskeletal reorganization (Witte and Bradke, 2008; Jurberg et al., 2014). Here, it needs to be underscored that these processes of signal transductions require directional and robust vesicle trafficking that cytoskeletal proteins regulate. For instance, directional vesicle trafficking from cell rear edge to leading edge may play crucial roles on cell migration. Thus in a manner similar to establishment of cell polarity by directing the localization of fate determining proteins, filamins, formins and RhoGTPases can coordinate similar processes during neural migration.

The functional roles of actin cytoskeletal genes in adhesion junctions and cell migration are also mutually interdependent. In the developing cerebral cortex, radial glial cells extend their end feet onto the apical lining of ventricle, where they form dense cell to cell/matrix connections via cell adhesion proteins like cadherins and integrins at the tips of the end feet. Newborn neuron or pre-neuron migrate out of ventricle along the radial glial fibers. Thus, loss of cytoskeletal-associated proteins causes destabilization of the interdependent adhesion complex (adhesion proteins and actin filament) and disconnection of radial glial at the apical lining. Impairment in the connection 
of radial glial end feet would interrupt migration along the radial glial tracks, thereby contributing to the neuronal migration defect. In addition, actin cytoskeletal and adhesion proteins are also enriched within the growth cone of migrating neuron. Loss of these proteins and/or disruption of their trafficking likely influence neuronal migration itself.

Finally, neural migration is dependent on the differentiation state of the precursor. For example, Rac1 is necessary for neural progenitor transition from G1 to $S$ phase, at least in part by regulating cyclin $\mathrm{D}$ levels and retinoblastoma protein phosphorylation. Loss of Racl in progenitors impairs the migration of ventral GABAergic neurons into the cortical plate. Ablation of Rac1 from postmitotic progenitors does not result in similar defects (Vidaki et al., 2012).

\section{Cytoskeletal-Associated Vesicle Trafficking: A Common Thread in Brain Development}

Vesicle trafficking maintains the apical-basal polarity of neuroepithelium through directional vesicle transport and membrane protein sorting (transcytosis), thus underlying cell polarity, migration and asymmetric division (Rodriguez-Boulan et al., 2005). Vesicle trafficking includes endocytosis, exocytosis and endosomal recycling and sorting (Symons and Rusk, 2003). Endocytic trafficking is characterized by the internalization of plasma membrane and extracellular molecules via several distinct pathways: micropinocytosis, phagocytosis, and clathrin and caveolae-mediated endocytosis. This process is dependent on actin cytoskeletal-associated proteins like Rho GTPases (Ridley, 2006). For example, dominant-negative Cdc42 or Rac1 can block macropinocytosis, while constitutively active Cdc42 and Racl can restore the pinocytosis in immature dendritic cells (Garrett et al., 2000). Actin dynamics is also crucial for phagocytosis. Both Cdc42 and Rac participate in Fc $\gamma \mathrm{R}$-mediated phagocytosis with Cdc42 directing pseudopod extension, and Rac functioning in pseudopod fusion and phagosome closure (Massol et al., 1998). During clathrin-mediated endocytosis, overexpression of constitutively active Racl and RhoA inhibits clathrin-mediated internalization of transferrin and EGF receptor in Hela cells (Lamaze et al., 1996), whereas RhoA can stimulate this process in polarized MDCK cells, suggesting that Rho GTPase function is dependent on cell polarity state (Leung et al., 1999). Caveolae are comprised of cholesterol-enriched internalized plasma membrane and are closely associated with actin filament. Integrins with caveolin have been shown to mediate RhoA activity in endothelial cells. Both RhoA and caveolin must co-localize and interact to mediate RhoA dependent actin remodeling (Nuno et al., 2009; Yang et al., 2011).

Formin and filamin proteins have been increasingly implicated in vesicle trafficking. MDia, together with myosin II, controls the initiation of E-cadherin endocytosis in the epithelium by regulating the lateral clustering of E-cadherin (Levayer et al., 2011). In oocytes, long-range transport of vesicles is regulated by Fmn2 through assembling an extensive actin network from the vesicles' surfaces to plasma membrane. The vesicles move directionally along these actin cables to reach the cell surface (Schuh, 2011). Recent work also reveals that filamin binds to the caveolae marker, caveolin, and is required for endocytic trafficking of caveolin (Muriel et al., 2011). The endocytic trafficking of caveolae towards a recycling endosome is impaired in FLNA-deficient HeLa and M2-melanoma cells.

Besides the effect on endocytic trafficking, actin cytoskeletalassociated proteins may also be involved in exocytosis. Actin-associated proteins (filamin, myosins and Cdc42) are present in the Golgi complex, and actin filament may function as tracks for the myosin-driven movement of vesicles. Expression of Cdc42 mutants slows the exit of the basolateral marker $\mathrm{N}$-cadherin from the trans-Golgi network while also stimulating the exit of the apical marker neurotrophin receptor p75 (Musch et al., 2001). RhoGTPases associate with the Golgi apparatus in an ARF-dependent manner. The ADP ribosylation factor guanine exchange factor 2 (ARFGEF2 encodes for BIG2) is a guanine nucleotide-exchange factor for ARF1/3, which play an important role in vesicular trafficking from Golgi complex to plasma membrane. Inhibition of BIG2 disrupts membranous localization of adherens junction protein E-cadherin and betacatenin by preventing their transport from the Golgi apparatus to the cell surface, leading to PH formation (Sheen et al., 2004; Zhang et al., 2012, 2013). Given that filamin can physically bind and interact with ARFGEF2 (Zhang et al., 2012), filamin and its associated proteins might orchestrate the vesicle exocytosis from Golgi to plasma membrane.

\section{Genetics of Periventricular Heterotopia}

Periventricular heterotopia is one of the most common malformation of cortical development and causes seizures, dyslexia, and psychiatric disturbances (Sheen, 2012). PH is characterized by bilateral ectopic neuronal nodules found along the lateral ventricles ( $\mathrm{Lu}$ and Sheen, 2005). The nodules are caused by impaired migration from the ventricular zone and disruption in the integrity of the neuroependyma (Sheen, 2012). Mutations in the causative genes also cause microcephaly (meaning small brain) (Sheen et al., 2003, 2004).

The most common form of $\mathrm{PH}$ is inherited in an X-linked dominant fashion from mutations in the FLNA gene (Fox et al., 1998; Sheen et al., 2001, 2005). A second form of autosomal recessive $\mathrm{PH}$ with microcephaly (ARPHM) has been associated with mutations in the ARFGEF2 gene. ARFGEF2 encodes brefeldin-A inhibited guanine exchange factor-2 (BIG2) (Sheen et al., 2004). BIG2 is a protein kinase A anchoring protein (AKAP) which regulates Golgi-vesicle trafficking through its Sec7 domain. Recent work has identified cadherin receptor ligands in causing PH due to mutations in FAT4 and DCHS1 (Cappello et al., 2013).

Several mouse genes have been shown to cause $\mathrm{PH}$ formation and can be functionally linked. aSNAP is a SNARE-related protein, involved in vesicle fusion. Prior reports have shown that $\alpha$ SNAP mediates VE-cadherin localization through a $\beta 1$-integrin-associated process (Andreeva et al., 2005). FlnA binds $\beta 1$-integrin (Calderwood et al., 2001). Mekk4 binds and 
regulates FlnA (Chi et al., 2005), and therefore could indirectly regulate caveolin mediated endocytosis. The RhoGTPases bind FlnA and direct various aspects of intracellular actin dynamics, which are required for endosomal vesicle transport (Cappello et al., 2006; Katayama et al., 2011). Deficiency of the formin associated $\mathrm{mDia}$ disrupts integrity of neuroepithelium and causes periventricular dysplasia (Thumkeo et al., 2011). Similarly, Spred1 is a multidomain scaffolding protein that contains an ENA/VASP domain which modulates actin stress fiber remodeling, like filamins. Spred1 is also associated with specific endosomal vesicles (Phoenix and Temple, 2010). Finally, SCF-ckit affects several downstream pathways including RAS/ERK and JAK/STAT pathways, both of which have been associated with Mekk4 and Spred1 activity (Rönnstrand, 2004; Soumiya et al., 2009).

Similar radiographic or anatomical findings of $\mathrm{PH}$ and potentially linked functions suggest that genes causal for $\mathrm{PH}$ might be involved in a common molecular pathway important in neural progenitor development. Prior studies have demonstrated a shared interaction between FlnA and Big2 in activating Arf to form vesicles at the cell membrane, and thereby regulate turnover/stability of cell adhesion molecules (Zhang et al., 2012, 2013).

\section{Anatomical Phenotypes Associated with PH}

Periventricular heterotopia refers to heterotopic neurons along the lateral ventricles which are caused by impaired motility/migration and disruption of the neuroependymal lining. For example, loss of FlnA results in fewer post mitotic cells reaching the cortical plate compared to wild type (WT) following BrdU incorporation. Cells remain in the intermediate and ventricular zones, consistent with a cell autonomous migratory defect (Zhang et al., 2013). Disruption in the neuroependymal lining has also been reported with FlnA inhibition (Adams et al., 2012). Loss of neuroependymal integrity is the primary cause of heterotopia formation.

While human and mouse genes associated with $\mathrm{PH}$ show brain heterotopia, they all also regulate neural proliferation. Human ARFGEF2 mutations cause microcephaly. While microcephaly is not seen in females with FLNA mutations (likely due to mosaicism), males die at birth and have been reported to have thinner cortices, and loss of cortical convolutions consistent with underlying microcephaly (Guerrini et al., 2004). Human mutations in cadherin-associated DCHS1 and FAT4 alter progenitor proliferation (Cappello et al., 2013). FlnA null mice also have microcephaly (Lian et al., 2012). Disruption of $\mathrm{Cdc} 42$ and RhoA cause $\mathrm{PH}$ in mice and lead to changes in brain size and/or progenitor proliferation (Cappello et al., 2006; Katayama et al., 2011). Dysregulation of PH associated Napa, Stem Cell Factor 1 (SCF) and Spred1 genes also alter progenitor proliferation in mice (Chae et al., 2004; Ferland et al., 2009; Phoenix and Temple, 2010). Mekk4 loss causes $\mathrm{PH}$ and a smaller brain with increased cell death (Chi et al., 2005). Formins have been implicated in proliferation of mouse neuroepithelial cells (Thumkeo et al., 2011). Lastly, a nonsense

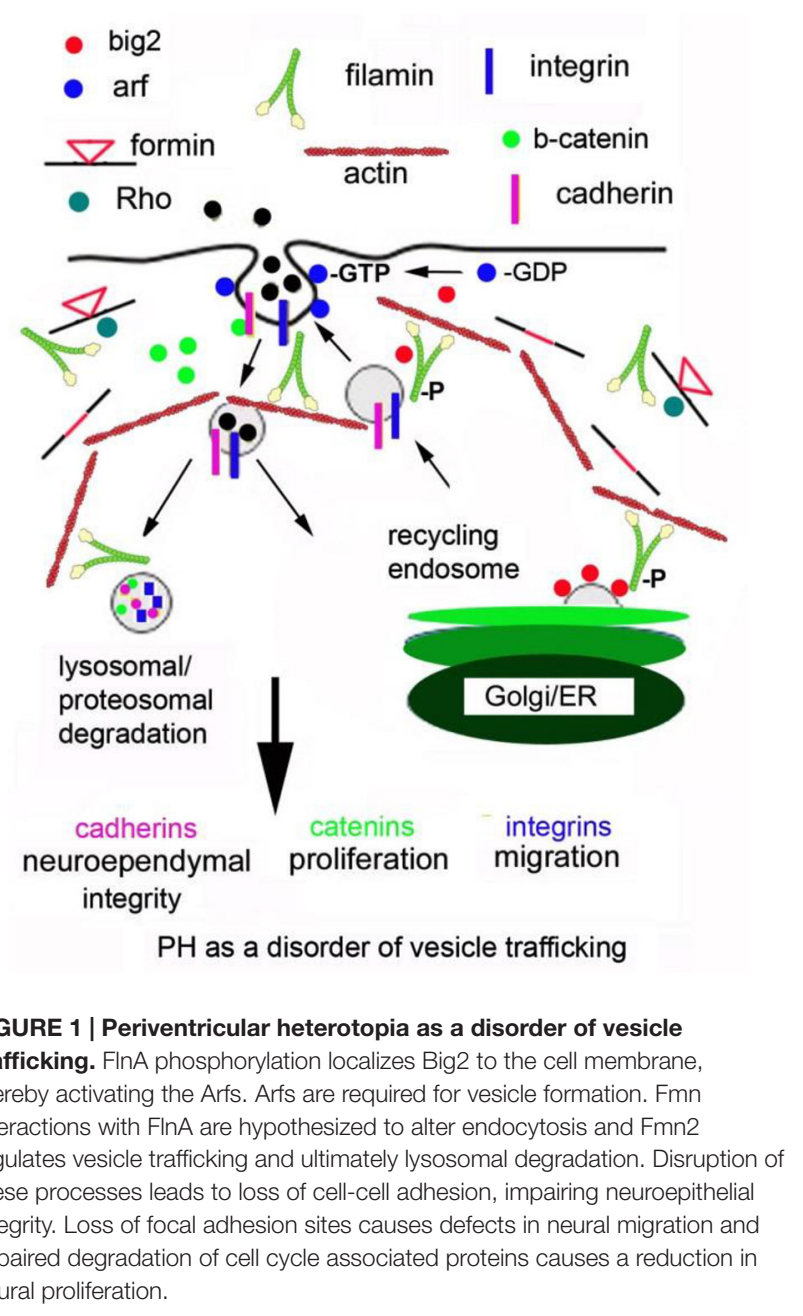

mutation of the formin related DIAPH1 (human mDia1) in humans has been found to cause microcephaly (Ercan-Sencicek et al., 2015).

There are several reasons to believe that the heterotopia formation, disruption in neuroependyma integrity, and impairments in neural proliferation are integrally linked. First, from an anatomical basis, FlnA loss leads to a smaller brain through prolongation in cell progression through mitosis (M) phase (Lian et al., 2012). In cortical development, $M$ phase occurs at the neuroepithelial lining suggesting a shared mechanism with $\mathrm{PH}$ formation (defects in adhesion/migration also occur at the neurependyma). Second, from a molecular standpoint, we have shown that Big2/FlnA regulate turnover of adhesion molecules (catenins and cadherins) at the neuroependyma (Zhang et al., 2013). These molecules have been show to regulate brain size and their associated molecules cause PH (Chenn and Walsh, 2002; Cappello et al., 2013). Lastly, a delay in differentiation would also lead to a delay in neural migration into the cortical plate.

\section{Cellular and Molecular Mechanisms in PH}

Periventricular heterotopia was initially thought to derive from a simple failure in neuronal migration given FLNA's regulation 
of the actin cytoskeleton (Fox et al., 1998). However, several observations indicate that $\mathrm{PH}$ formation may be more complex, derived from diverse processes associated with cytoskeletal dynamics. First, BrdU labeling shows that loss of FlnA in developing mouse brain results in slower migration of neurons, but no $\mathrm{PH}$ formation, implying that the impairment in neuronal migration may not be the primary reason for $\mathrm{PH}$ formation (Zhang et al., 2013). Second, conditional deletion of RhoA in developing brain causes severe $\mathrm{PH}$ formation, but loss of RhoA does not impair neuronal migration (Katayama et al., 2011; Cappello, 2013). Third, as more genes causative for $\mathrm{PH}$ are identified, their shared function would argue that adherens junctions and actin cytoskeletal dynamics along the ventricular lining may be the primary pivotal factor for $\mathrm{PH}$ formation (Brault et al., 2001; Machon et al., 2003; Chae et al., 2004; Sheen et al., 2004; Kadowaki et al., 2007; Ma et al., 2007; Thumkeo et al., 2011; Peng et al., 2013). Consistent with this view are the findings that the actin filament network around the heterotopia in the $\mathrm{PH}$ brains is disrupted (Ferland et al., 2009). Concomitantly, the expression of neuroepithelial polarity and adherens junction proteins along the apical lining decreases or disappears.

Recent studies from this laboratory have begun to reconcile how two seemingly dissimilar proteins Big2 and FlnA can give rise to $\mathrm{PH}$ (Zhang et al., 2012, 2013). Either acute or chronic loss of either Big2 or FlnA leads to impairments in neural migration during development of the cortex. Migratory neural cells show defects in filopodia extension and attachment onto extracellular matrix coated surfaces. Both proteins physically bind and interact within neural progenitors, and loss of protein expression of either FlnA or Big2 leads to compensatory upregulation of the other. As with many proteins that FlnA binds, Big2 localization is dependent on phosphorylation of the actin binding protein which redirects Big2 from the Golgi to the cell membrane. Relocalization to the membrane allows Big2 to activate Arf1. Arfs have been shown to reside at the cell surface with ARF1 and ARF3 mediating endocytosis (Dong et al., 2010; Kondo et al., 2012). The reciprocal regulation likely reflects a negative feedback, where loss of Big2 promotes phospho-FlnA expression to enhance redistribution of Big2 to the membrane. Conversely, loss of FlnA enhances Big2 expression to allow for Big2 delivery to the membrane. These studies begin to suggest an integral relationship between FlnA dependent actin dynamics and Big2 dependent regulation of vesicle formation and trafficking.

\section{Periventricular Heterotopia as a Disorder of Vesicle Trafficking}

Changes in Arf-dependent endocytosis have the potential to disrupt several cell developmental processes and provide a hypothetical model for $\mathrm{PH}$ formation (see the cartoon in Figure 1; Sheen, 2012). First, the primary anatomical defect leading to the $\mathrm{PH}$ phenotype (loss in neuroependymal integrity, impaired migration, and reduced proliferation) occurs within neural progenitors along the neuroepithelial lining. Genes implicated in $\mathrm{PH}$ (FlnA, Big2) regulate the stability, turnover and degradation of cell adhesion molecules ( $\beta$-catenin, $N$-cadherin) and cell-ECM receptors (integrins, paxillin adaptor proteins).
FlnA phosphorylation targets Big2 to the membrane, allowing for Arf-dependent activation and vesicle formation. Endocytosis occurs through a caveolin dependent mechanism leading to internalization of catenin/cadherin and integrins. Specificity for these molecules extends from their binding of filamins (Calderwood et al., 2001). Several associated PH genes (RhoA, $\alpha$ SNAP and Spred1) would be expected to participate in this process given their implied association with trafficking and/or endocytosis but their specific roles are not known. The downstream mechanisms that regulate endosomal and lysosomal/proteosomal processing in contributing to $\mathrm{PH}$ are also not known, although this review would point to a RhoA and Fmn dependent process.

In short, disruption of Big2 and FlnA (and presumably Fmn and RhoGTPases) would alter the stabilization, turnover and degradation of the cadherin, catenin and integrin proteins through impaired vesicle trafficking. Loss of cell adhesion (via altered cadherin) would disrupt the neuroependymal lining. Impaired cadherin stability would also alter catenin localization and function, thereby leading to impaired proliferation. Alteration of cell fate would be closely linked to proliferation and also effect neural migration. For example, slower progression through the cell cycle (as seen with loss of FlnA) causes delayed differentiation of neural progenitors at a given age (as seen with enhanced symmetric cell divisions from FlnA loss). This delayed differentiation would also lead to slower neural migration from the ventricular zone into the cortical plate. In this respect, many of the phenotypes seen with $\mathrm{PH}$ can be explained through changes in actin cytoskeletal regulation via FlnA-RhoA-Fmn2 (and Big2) within neural cells along the ventricular lining.

\section{Conclusion}

Actin cytoskeletal-associated proteins play a variety of diverse and key roles in cerebral cortex development. A basic mechanism for filamins, formins and RhoGTPases may extend from their regulation of dynamic vesicle trafficking, in directed neural progenitor development. Directional transport of actin cytoskeletal-associated vesicles toward apicolateral or basolateral membranes along the neuroepithelium may be crucial for establishing polarity and maintaining adherens junctions. Loss of this function appears to be the primary pathology underlying $\mathrm{PH}$ formation. Cytoskeletal-regulated vesicle trafficking may transmit extracellular signals into cytoplasm and nucleus, as well as mediate degradation of cell cycle associated proteins, thereby regulating cell cycle progression and proliferation. $\mathrm{PH}$ has been associated with microcephaly. Finally, directional vesicle trafficking, as well as regulation of turnover of proteins toward the leading edge of migratory neural cells, would be required for proper neuronal migration, and account for the impaired migration seen in this disorder.

\section{Acknowledgments}

This work was supported in part by the National Institutes of Health (1 R01 NS092062 01 to VLS). 


\section{References}

Adams, M., Simms, R. J., Abdelhamed, Z., Dawe, H. R., Szymanska, K., Logan, C. V., et al. (2012). A meckelin-filamin A interaction mediates ciliogenesis. Hum. Mol. Genet. 21, 1272-1286. doi: 10.1093/hmg/ddr557

Andreeva, A. V., Kutuzov, M. A., Vaiskunaite, R., Profirovic, J., Meigs, T. E., Predescu, S., et al. (2005). G alpha12 interaction with alphaSNAP induces VEcadherin localization at endothelial junctions and regulates barrier function. $J$. Biol. Chem. 280, 30376-30383. doi: 10.1074/jbc.m502844200

Azzarelli, R., Pacary, E., Garg, R., Garcez, P., van den Berg, D., Riou, P., et al. (2014). An antagonistic interaction between PlexinB2 and Rnd3 controls RhoA activity and cortical neuron migration. Nat. Commun. 5:3405. doi: 10. 1038/ncomms4405

Barros, C. S., Phelps, C. B., and Brand, A. H. (2003). Drosophila nonmuscle myosin II promotes the asymmetric segregation of cell fate determinants by cortical exclusion rather than active transport. Dev. Cell 5, 829-840. doi: 10.1016/s15345807(03)00359-9

Basu, R., and Chang, F. (2007). Shaping the actin cytoskeleton using microtubule tips. Curr. Opin. Cell Biol. 19, 88-94. doi: 10.1016/j.ceb.2006.12.012

Bohmer, R. M., Scharf, E., and Assoian, R. K. (1996). Cytoskeletal integrity is required throughout the mitogen stimulation phase of the cell cycle and mediates the anchorage-dependent expression of cyclin D1. Mol. Biol. Cell 7, 101-111. doi: 10.1091/mbc.7.1.101

Bork, P., and Sudol, M. (1994). The WW domain: a signalling site in dystrophin? Trends Biochem. Sci. 19, 531-533. doi: 10.1016/0968-0004(94)90053-1

Bovellan, M., Romeo, Y., Biro, M., Boden, A., Chugh, P., Yonis, A., et al. (2014). Cellular control of cortical actin nucleation. Curr. Biol. 24, 1628-1635. doi: 10. 1016/j.cub.2014.05.069

Brault, V., Moore, R., Kutsch, S., Ishibashi, M., Rowitch, D. H., McMahon, A. P., et al. (2001). Inactivation of the beta-catenin gene by Wnt1-Cre-mediated deletion results in dramatic brain malformation and failure of craniofacial development. Development 128, 1253-1264.

Broussard, J. A., Webb, D. J., and Kaverina, I. (2008). Asymmetric focal adhesion disassembly in motile cells. Curr. Opin. Cell Biol. 20, 85-90. doi: 10.1016/j.ceb. 2007.10.009

Calderwood, D. A., Huttenlocher, A., Kiosses, W. B., Rose, D. M., Woodside, D. G., Schwartz, M. A., et al. (2001). Increased filamin binding to beta-integrin cytoplasmic domains inhibits cell migration. Nat. Cell Biol. 3, 1060-1068. doi: $10.1038 /$ ncb1201-1060

Cao, J., Crest, J., Fasulo, B., and Sullivan, W. (2010). Cortical actin dynamics facilitate early-stage centrosome separation. Curr. Biol. 20, 770-776. doi: 10. 1016/j.cub.2010.02.060

Cappello, S. (2013). Small Rho-GTPases and cortical malformations: fine-tuning the cytoskeleton stability. Small GTPases 4, 51-56. doi: 10.4161/sgtp.23093

Cappello, S., Attardo, A., Wu, X., Iwasato, T., Itohara, S., Wilsch-Brauninger, M., et al. (2006). The Rho-GTPase cdc42 regulates neural progenitor fate at the apical surface. Nat. Neurosci. 9, 1099-1107. doi: 10.1038/nn1744

Cappello, S., Gray, M. J., Badouel, C., Lange, S., Einsiedler, M., Srour, M., et al. (2013). Mutations in genes encoding the cadherin receptor-ligand pair DCHS1 and FAT4 disrupt cerebral cortical development. Nat. Genet. 45, 1300-1308. doi: $10.1038 /$ ng. 2765

Chae, T. H., Kim, S., Marz, K. E., Hanson, P. I., and Walsh, C. A. (2004). The hyh mutation uncovers roles for alpha Snap in apical protein localization and control of neural cell fate. Nat. Genet. 36, 264-270. doi: 10.1038/ng1302

Chen, X., and Friml, J. (2014). Rho-GTPase-regulated vesicle trafficking in plant cell polarity. Biochem. Soc. Trans. 42, 212-218. doi: 10.1042/BST20 130269

Chen, L., Liao, G., Waclaw, R. R., Burns, K. A., Linquist, D., Campbell, K., et al. (2007). Rac1 controls the formation of midline commissures and the competency of tangential migration in ventral telencephalic neurons. $J$. Neurosci. 27, 3884-3893. doi: 10.1523/jneurosci.3509-06.2007

Chen, L., Liao, G., Yang, L., Campbell, K., Nakafuku, M., Kuan, C. Y., et al. (2006). Cdc42 deficiency causes Sonic hedgehog-independent holoprosencephaly. Proc. Natl. Acad. Sci. U S A 103, 16520-16525. doi: 10.1073/pnas.06035 33103

Chenn, A., and Walsh, C. A. (2002). Regulation of cerebral cortical size by control of cell cycle exit in neural precursors. Science 297, 365-369. doi: 10. 1126/science. 1074192
Chi, H., Sarkisian, M. R., Rakic, P., and Flavell, R. A. (2005). Loss of mitogenactivated protein kinase kinase kinase 4 (MEKK4) results in enhanced apoptosis and defective neural tube development. Proc. Natl. Acad. Sci. U S A 102, 3846-3851. doi: 10.1073/pnas.0500026102

Ciobanasu, C., Faivre, B., and Le Clainche, C. (2013). Integrating actin dynamics, mechanotransduction and integrin activation: the multiple functions of actin binding proteins in focal adhesions. Eur. J. Cell Biol. 92, 339-348. doi: 10.1016/j. ejcb.2013.10.009

Coleman, M. L., Densham, R. M., Croft, D. R., and Olson, M. F. (2006). Stability of p21Waf1/Cip1 CDK inhibitor protein is responsive to RhoA-mediated regulation of the actin cytoskeleton. Oncogene 25, 2708-2716. doi: 10.1038/sj. onc. 1209322

Cook, D. R., Rossman, K. L., and Der, C. J. (2014). Rho guanine nucleotide exchange factors: regulators of Rho GTPase activity in development and disease. Oncogene 33, 4021-4035. doi: 10.1038/onc.2013.362

Cox, D., Wessels, D., Soll, D. R., Hartwig, J., and Condeelis, J. (1996). Reexpression of ABP-120 rescues cytoskeletal, motility and phagocytosis defects of ABP-120- Dictyostelium mutants. Mol. Biol. Cell 7, 803-823. doi: 10. $1091 / \mathrm{mbc} .7 .5 .803$

Cremisi, F., Philpott, A., and Ohnuma, S. (2003). Cell cycle and cell fate interactions in neural development. Curr. Opin. Neurobiol. 13, 26-33. doi: 10. 1016/s0959-4388(03)00005-9

Cunningham, C. C., Gorlin, J. B., Kwiatkowski, D. J., Hartwig, J. H., Janmey, P. A., Byers, H. R., et al. (1992). Actin-binding protein requirement for cortical stability and efficient locomotion. Science 255, 325-327. doi: 10.1126/science. 1549777

Dong, C., Zhang, X., Zhou, F., Dou, H., Duvernay, M. T., Zhang, P., et al. (2010). ADP-ribosylation factors modulate the cell surface transport of G proteincoupled receptors. J. Pharmacol. Exp. Ther. 333, 174-183. doi: 10.1124/jpet.109. 161489

Drechsel, D. N., Hyman, A. A., Hall, A., and Glotzer, M. (1997). A requirement for Rho and Cdc42 during cytokinesis in Xenopus embryos. Curr. Biol. 7, 12-23. doi: 10.1016/s0960-9822(06)00023-6

Duong, T., De Rosa, M. J., Poukens, V., Vinters, H. V., and Fisher, R. S. (1994). Neuronal cytoskeletal abnormalities in human cerebral cortical dysplasia. Acta Neuropathol. 87, 493-503. doi: 10.1007/bf00294176

Ercan-Sencicek, A. G., Jambi, S., Franjic, D., Nishimura, S., Li, M., El-Fishawy, P., et al. (2015). Homozygous loss of DIAPH1 is a novel cause of microcephaly in humans. Eur. J. Hum. Genet. 23, 165-172. doi: 10.1038/ejhg.2014.82

Etienne-Manneville, S. (2004). Cdc42-the centre of polarity. J. Cell Sci. 117(Pt. 8), 1291-1300. doi: 10.1242/jcs.01115

Feng, Y., Chen, M. H., Moskowitz, I. P., Mendonza, A. M., Vidali, L., Nakamura, F., et al. (2006). Filamin A (FLNA) is required for cell-cell contact in vascular development and cardiac morphogenesis. Proc. Natl. Acad. Sci. U S A 103, 19836-19841. doi: 10.1073/pnas.0609628104

Ferland, R. J., Batiz, L. F., Neal, J., Lian, G., Bundock, E., Lu, J., et al. (2009). Disruption of neural progenitors along the ventricular and subventricular zones in periventricular heterotopia. Hum. Mol. Genet. 18, 497-516. doi: 10. 1093/hmg/ddn377

Fox, J. W., Lamperti, E. D., Ekioğlu, Y. Z., Hong, S. E., Feng, Y., Graham, D. A., et al. (1998). Mutations in filamin 1 prevent migration of cerebral cortical neurons in human periventricular heterotopia. Neuron 21, 1315-1325. doi: 10. 1016/s0896-6273(00)80651-0

Fox, J. W., and Walsh, C. A. (1999). Periventricular heterotopia and the genetics of neuronal migration in the cerebral cortex. Am. J. Hum. Genet. 65, 19-24. doi: $10.1086 / 302474$

Fried, S., Matalon, O., Noy, E., and Barda-Saad, M. (2014). WIP: more than a WASp-interacting protein. J. Leukoc. Biol. 96, 713-727. doi: 10.1189/jlb. 2ru0314-162r

Garrett, W. S., Chen, L. M., Kroschewski, R., Ebersold, M., Turley, S., Trombetta, S., et al. (2000). Developmental control of endocytosis in dendritic cells by Cdc42. Cell 102, 325-334. doi: 10.1016/s0092-8674(00)00038-6

Gonzalez-Billault, C., Muñoz-Llancao, P., Henriquez, D. R., Wojnacki, J., Conde, C., and Caceres, A. (2012). The role of small GTPases in neuronal morphogenesis and polarity. Cytoskeleton (Hoboken) 69, 464-485. doi: 10. $1002 / \mathrm{cm} .21034$

Gorlin, J. B., Yamin, R., Egan, S., Stewart, M., Stossel, T. P., Kwiatkowski, D. J., et al. (1990). Human endothelial actin-binding protein (ABP-280, nonmuscle 
filamin): a molecular leaf spring. J. Cell Biol. 111, 1089-1105. doi: 10.1083/jcb. 111.3.1089

Götz, M., and Huttner, W. B. (2005). The cell biology of neurogenesis. Nat. Rev. Mol. Cell Biol. 6, 777-788. doi: 10.1038/nrm1739

Gould, C. J., Maiti, S., Michelot, A., Graziano, B. R., Blanchoin, L., and Goode, B. L. (2011). The formin DAD domain plays dual roles in autoinhibition and actin nucleation. Curr. Biol. 21, 384-390. doi: 10.1016/j.cub.2011.01.047

Govek, E. E., Newey, S. E., and Van Aelst, L. (2005). The role of the Rho GTPases in neuronal development. Genes Dev. 19, 1-49. doi: 10.1101/gad.1256405

Guerrini, R., Mei, D., Sisodiya, S., Sicca, F., Harding, B., Takahashi, Y., et al. (2004). Germline and mosaic mutations of FLN1 in men with periventricular heterotopia. Neurology 63, 51-56. doi: 10.1212/01.wnl.0000132818.84827.4d

Guo, M., Jan, L. Y., and Jan, Y. N. (1996). Control of daughter cell fates during asymmetric division: interaction of Numb and Notch. Neuron 17, 27-41. doi: 10.1016/S0896-6273(00)80278-0

Habas, R., Kato, Y., and He, X. (2001). Wnt/Frizzled activation of Rho regulates vertebrate gastrulation and requires a novel Formin homology protein Daam1. Cell 107, 843-854. doi: 10.1016/s0092-8674(01)00614-6

Hart, A. W., Morgan, J. E., Schneider, J., West, K., McKie, L., Bhattacharya, S., et al. (2006). Cardiac malformations and midline skeletal defects in mice lacking filamin A. Hum. Mol. Genet. 15, 2457-2467. doi: 10.1093/hmg/ddl168

Heng, Y. W., and Koh, C. G. (2010). Actin cytoskeleton dynamics and the cell division cycle. Int. J. Biochem. Cell Biol. 42, 1622-1633. doi: 10.1016/j.biocel. 2010.04.007

Heng, J. I., Nguyen, L., Castro, D. S., Zimmer, C., Wildner, H., Armant, O., et al. (2008). Neurogenin 2 controls cortical neuron migration through regulation of Rnd2. Nature 455, 114-118. doi: 10.1038/nature07198

Hild, G., Kalmár, L., Kardos, R., Nyitrai, M., and Bugyi, B. (2014). The other side of the coin: functional and structural versatility of ADF/cofilins. Eur. J. Cell Biol. 93, 238-251. doi: 10.1016/j.ejcb.2013.12.001

Hu, J., Lu, J., Lian, G., Ferland, R. J., Dettenhofer, M., and Sheen, V. L. (2014). Formin 1 and filamin B physically interact to coordinate chondrocyte proliferation and differentiation in the growth plate. Hum. Mol. Genet. 23, 4663-4673. doi: 10.1093/hmg/ddu186

Iden, S., and Collard, J. G. (2008). Crosstalk between small GTPases and polarity proteins in cell polarization. Nat. Rev. Mol. Cell Biol. 9, 846-859. doi: 10. 1038/nrm2521

Jurberg, A. D., Aires, R., Nóvoa, A., Rowland, J. E., and Mallo, M. (2014). Compartment-dependent activities of Wnt3a/beta-catenin signaling during vertebrate axial extension. Dev. Biol. 394, 253-263. doi: 10.1016/j.ydbio.2014. 08.012

Kadowaki, M., Nakamura, S., Machon, O., Krauss, S., Radice, G. L., and Takeichi, M. (2007). N-cadherin mediates cortical organization in the mouse brain. Dev. Biol. 304, 22-33. doi: 10.1016/j.ydbio.2006.12.014

Katayama, K., Melendez, J., Baumann, J. M., Leslie, J. R., Chauhan, B. K., Nemkul, N., et al. (2011). Loss of RhoA in neural progenitor cells causes the disruption of adherens junctions and hyperproliferation. Proc. Natl. Acad. Sci. U S A 108, 7607-7612. doi: 10.1073/pnas.1101347108

Khaitlina, S. Y. (2014). Intracellular transport based on actin polymerization. Biochemistry (Mosc) 79, 917-927. doi: 10.1134/s0006297914090089

Knoblich, J. A. (2008). Mechanisms of asymmetric stem cell division. Cell 132, 583-597. doi: 10.1016/j.cell.2008.02.007

Kondo, Y., Hanai, A., Nakai, W., Katoh, Y., Nakayama, K., and Shin, H. W. (2012). ARF1 and ARF3 are required for the integrity of recycling endosomes and the recycling pathway. Cell Struct. Funct. 37, 141-154. doi: 10.1247/csf.12015

Krakow, D., Robertson, S. P., King, L. M., Morgan, T., Sebald, E. T., Bertolotto, C., et al. (2004). Mutations in the gene encoding filamin B disrupt vertebral segmentation, joint formation and skeletogenesis. Nat. Genet. 36, 405-410. doi: $10.1038 /$ ng1319

Lamaze, C., Chuang, T. H., Terlecky, L. J., Bokoch, G. M., and Schmid, S. L. (1996). Regulation of receptor-mediated endocytosis by Rho and Rac. Nature 382, 177-179. doi: $10.1038 / 382177 \mathrm{a} 0$

Lee, K., and Song, K. (2007). Actin dysfunction activates ERK1/2 and delays entry into mitosis in mammalian cells. Cell Cycle 6, 1487-1495. doi: 10.4161/cc.6.12. 4303

Leone, D. P., Srinivasan, K., Brakebusch, C., and McConnell, S. K. (2010). The rho GTPase Rac1 is required for proliferation and survival of progenitors in the developing forebrain. Dev. Neurobiol. 70, 659-678. doi: 10.1002/dneu.20804
Leung, S. M., Rojas, R., Maples, C., Flynn, C., Ruiz, W. G., Jou, T. S., et al. (1999). Modulation of endocytic traffic in polarized Madin-Darby canine kidney cells by the small GTPase RhoA. Mol. Biol. Cell 10, 4369-4384. doi: 10.1091/mbc.10. 12.4369

Levayer, R., Pelissier-Monier, A., and Lecuit, T. (2011). Spatial regulation of Dia and Myosin-II by RhoGEF2 controls initiation of E-cadherin endocytosis during epithelial morphogenesis. Nat. Cell Biol. 13, 529-540. doi: 10. 1038/ncb2224

Lian, G., Lu, J., Hu, J., Zhang, J., Cross, S. H., Ferland, R. J., et al. (2012), Filamin a regulates neural progenitor proliferation and cortical size through Wee1-dependent Cdk1 phosphorylation. J. Neurosci. 32, 7672-7684. doi: 10. 1523/JNEUROSCI.0894-12.2012

Lu, J., and Sheen, V. (2005). Periventricular heterotopia. Epilepsy Behav. 7, 143-149. doi: 10.1016/j.yebeh.2005.05.001

Ma, X., and Adelstein, R. S. (2014). The role of vertebrate nonmuscle Myosin II in development and human disease. Bioarchitecture 4, 88-102. doi: 10.4161/bioa. 29766

Ma, X., Bao, J., and Adelstein, R. S. (2007). Loss of cell adhesion causes hydrocephalus in nonmuscle myosin II-B-ablated and mutated mice. Mol. Biol. Cell 18, 2305-2312. doi: 10.1091/mbc.e07-01-0073

Machon, O., van den Bout, C. J., Backman, M., Kemler, R., and Krauss, S. (2003). Role of beta-catenin in the developing cortical and hippocampal neuroepithelium. Neuroscience 122, 129-143. doi: 10.1016/s03064522(03)00519-0

Maddox, A. S., and Burridge, K. (2003). RhoA is required for cortical retraction and rigidity during mitotic cell rounding. J. Cell Biol. 160, 255-265. doi: 10. 1083/jcb.200207130

Mammoto, A., Huang, S., and Ingber, D. E. (2007). Filamin links cell shape and cytoskeletal structure to Rho regulation by controlling accumulation of p190RhoGAP in lipid rafts. J. Cell Sci. 120(Pt. 3), 456-467. doi: 10.1242/jcs. 03353

Mammoto, A., Huang, S., Moore, K., Oh, P., and Ingber, D. E. (2004). Role of RhoA, mDia and ROCK in cell shape-dependent control of the Skp2-p27kip1 pathway and the G1/S transition. J. Biol. Chem. 279, 26323-26330. doi: 10 . 1074/jbc.m402725200

Massol, P., Montcourrier, P., Guillemot, J. C., and Chavrier, P. (1998). Fc receptormediated phagocytosis requires CDC42 and Rac1. EMBO J. 17, 6219-6229. doi: 10.1093/emboj/17.21.6219

Michaelson, D., Abidi, W., Guardavaccaro, D., Zhou, M., Ahearn, I., Pagano, M., et al. (2008). Racl accumulates in the nucleus during the G2 phase of the cell cycle and promotes cell division. J. Cell Biol. 181, 485-496. doi: 10.1083/jcb. 200801047

Minobe, S., Sakakibara, A., Ohdachi, T., Kanda, R., Kimura, M., Nakatani, S., et al. (2009). Rac is involved in the interkinetic nuclear migration of cortical progenitor cells. Neurosci. Res. 63, 294-301. doi: 10.1016/j.neures.2009. 01.006

Modarres, H. P., and Mofradt, M. R. (2014). Filamin: a structural and functional biomolecule with important roles in cell biology, signaling and mechanics. Mol. Cell Biomech. 11, 39-65. doi: 10.3970/mcb.2014.011.039

Moon, H. M., and Wynshaw-Boris, A. (2013). Cytoskeleton in action: lissencephaly, a neuronal migration disorder. Wiley Interdiscip. Rev. Dev. Biol. 2, 229-245. doi: 10.1002/wdev.67

Munro, E. M. (2006). PAR proteins and the cytoskeleton: a marriage of equals. Curr. Opin. Cell Biol. 18, 86-94. doi: 10.1016/j.ceb.2005.12.007

Murali, A., and Rajalingam, K. (2014). Small Rho GTPases in the control of cell shape and mobility. Cell Mol. Life Sci. 71, 1703-1721. doi: 10.1007/s00018-0131519-6

Muriel, O., Echarri, A., Hellriegel, C., Pavón, D. M., Beccari, L., and Del Pozo, M. A. (2011). Phosphorylated filamin A regulates actin-linked caveolae dynamics. J. Cell Sci. 124(Pt. 16), 2763-2776. doi: 10.1242/jcs.080804

Musch, A., Cohen, D., Kreitzer, G., and Rodriguez-Boulan, E. (2001). cdc42 regulates the exit of apical and basolateral proteins from the trans-Golgi network. EMBO J. 20, 2171-2179. doi: 10.1093/emboj/20.9.2171

Nag, S., Larsson, M., Robinson, R. C., and Burtnick, L. D. (2013). Gelsolin: the tail of a molecular gymnast. Cytoskeleton (Hoboken) 70, 360-384. doi: 10.1002/ $\mathrm{cm} .21117$

Nagano, T., Morikubo, S., and Sato, M. (2004). Filamin A and FILIP (Filamin A-Interacting Protein) regulate cell polarity and motility in neocortical 
subventricular and intermediate zones during radial migration. J. Neurosci. 24, 9648-9657. doi: 10.1523/jneurosci.2363-04.2004

Nagano, T., Yoneda, T., Hatanaka, Y., Kubota, C., Murakami, F., and Sato, M. (2002). Filamin A-interacting protein (FILIP) regulates cortical cell migration out of the ventricular zone. Nat. Cell Biol. 4, 495-501. doi: 10.1038/ ncb808

Nakamura, F., Stossel, T. P., and Hartwig, J. H. (2011). The filamins: organizers of cell structure and function. Cell Adh. Migr. 5, 160-169. doi: 10.4161/ cam.5.2.14401

Nomachi, A., Nishita, M., Inaba, D., Enomoto, M., Hamasaki, M., and Minami, Y. (2008). Receptor tyrosine kinase Ror2 mediates Wnt5a-induced polarized cell migration by activating c-Jun $\mathrm{N}$-terminal kinase via actin-binding protein filamin A. J. Biol. Chem. 283, 27973-27981. doi: 10.1074/jbc.M802325200

Nuno, D. W., Harrod, J. S., and Lamping, K. G. (2009). Sex-dependent differences in Rho activation contribute to contractile dysfunction in type 2 diabetic mice. Am. J. Physiol. Heart Circ. Physiol. 297, H1469-H1477. doi: 10.1152/ajpheart. 00407.2009

Ohno, S. (2001). Intercellular junctions and cellular polarity: the PAR-aPKC complex, a conserved core cassette playing fundamental roles in cell polarity. Curr. Opin. Cell Biol. 13, 641-648. doi: 10.1016/s0955-0674(00) 00264-7

Ohnuma, S., and Harris, W. A. (2003). Neurogenesis and the cell cycle. Neuron 40, 199-208. doi: 10.1016/S0896-6273(03)00632-9

Ohta, Y., Hartwig, J. H., and Stossel, T. P. (2006). FilGAP, a Rho- and ROCKregulated GAP for Rac binds filamin A to control actin remodelling. Nat. Cell Biol. 8, 803-814. doi: 10.1038/ncb1437

Okumura, A., Hayashi, M., Shimojima, K., Ikeno, M., Uchida, T., Takanashi, J., et al. (2013). Whole-exome sequencing of a unique brain malformation with periventricular heterotopia, cingulate polymicrogyria and midbrain tectal hyperplasia. Neuropathology 33, 553-560. doi: 10.1111/neup.12007

Olson, M. F., Ashworth, A., and Hall, A. (1995). An essential role for Rho, Rac and Cdc42 GTPases in cell cycle progression through G1. Science 269, 1270-1272. doi: $10.1126 /$ science. 7652575

Otey, C. A., and Carpen, O. (2004). Alpha-actinin revisited: a fresh look at an old player. Cell Motil. Cytoskeleton. 58, 104-111. doi: 10.1002/ cm. 20007

Otomo, T., Otomo, C., Tomchick, D. R., Machius, M., and Rosen, M. K. (2005). Structural basis of Rho GTPase-mediated activation of the formin mDial. Mol. Cell 18, 273-281. doi: 10.1016/j.molcel.2005.04.002

Pan, J., Lordier, L., Meyran, D., Rameau, P., Lecluse, Y., Kitchen-Goosen, S., et al. (2014). The formin DIAPH1 (mDia1) regulates megakaryocyte proplatelet formation by remodeling the actin and microtubule cytoskeletons. Blood 124, 3967-3977. doi: 10.1182/blood-2013-12-544924

Peng, X., Lin, Q., Liu, Y., Jin, Y., Druso, J. E., Antonyak, M. A., et al. (2013). Inactivation of $\mathrm{Cdc} 42$ in embryonic brain results in hydrocephalus with ependymal cell defects in mice. Protein Cell 4, 231-242. doi: 10.1007/s13238012-2098-2

Phoenix, T. N., and Temple, S. (2010). Spred1, a negative regulator of Ras-MAPKERK, is enriched in CNS germinal zones, dampens NSC proliferation and maintains ventricular zone structure. Genes Dev. 24, 45-56. doi: 10.1101/gad. 1839510

Raftopoulou, M., and Hall, A. (2004). Cell migration: Rho GTPases lead the way. Dev. Biol. 265, 23-32. doi: 10.1016/j.ydbio.2003.06.003

Razinia, Z., Mäkelä, T., Ylänne, J., and Calderwood, D. A. (2012). Filamins in mechanosensing and signaling. Annu. Rev. Biophys. 41, 227-246. doi: 10. 1146/annurev-biophys-050511-102252

Ridley, A. J. (2006). Rho GTPases and actin dynamics in membrane protrusions and vesicle trafficking. Trends Cell Biol. 16, 522-529. doi: 10.1016/j.tcb.2006. 08.006

Ridley, A. J., Schwartz, M. A., Burridge, K., Firtel, R. A., Ginsberg, M. H., Borisy, G., et al. (2003). Cell migration: integrating signals from front to back. Science 302, 1704-1709. doi: 10.1126/science.1092053

Rivas, R. J., and Hatten, M. E. (1995). Motility and cytoskeletal organization of migrating cerebellar granule neurons. J. Neurosci. 15, 981-989.

Robertson, S. P., Twigg, S. R., Sutherland-Smith, A. J., Biancalana, V., Gorlin, R. J., Horn, D., et al. (2003). Localized mutations in the gene encoding the cytoskeletal protein filamin A cause diverse malformations in humans. Nat. Genet. 33, 487-491. doi: 10.1038/ng1119
Rodriguez-Boulan, E., Kreitzer, G., and Müsch, A. (2005). Organization of vesicular trafficking in epithelia. Nat. Rev. Mol. Cell Biol. 6, 233-247. doi: 10. $1038 /$ nrm 1593

Rönnstrand, L. (2004). Signal transduction via the stem cell factor receptor/c-Kit. Cell. Mol. Life Sci. 61, 2535-2548. doi: 10.1007/s00018-004-4189-6

Rosenblatt, J., Cramer, L. P., Baum, B., and McGee, K. M. (2004). Myosin II-dependent cortical movement is required for centrosome separation and positioning during mitotic spindle assembly. Cell 117, 361-372. doi: 10. 1016/s0092-8674(04)00341-1

Rottner, K., and Stradal, T. E. (2011). Actin dynamics and turnover in cell motility. Curr. Opin. Cell Biol. 23, 569-578. doi: 10.1016/j.ceb.2011.07.003

Sawin, K. E. (2002). Cell polarity: following formin function. Curr. Biol. 12, R6-R8. doi: 10.1016/s0960-9822(01)00637-6

Schaar, B. T., and McConnell, S. K. (2005). Cytoskeletal coordination during neuronal migration. Proc. Natl. Acad. Sci. U S A 102, 13652-13657. doi: 10. 1073/pnas.0506008102

Schönichen, A., and Geyer, M. (2010). Fifteen formins for an actin filament: a molecular view on the regulation of human formins. Biochim. Biophys. Acta 1803, 152-163. doi: 10.1016/j.bbamcr.2010.01.014

Schuh, M. (2011). An actin-dependent mechanism for long-range vesicle transport. Nat. Cell Biol. 13, 1431-1436. doi: 10.1038/ncb2353

Sheen, V. L. (2012). Periventricular Heterotopia: shuttling of proteins through vesicles and actin in cortical development and disease. Scientifica (Cairo) 2012:480129. doi: 10.6064/2012/480129

Sheen, V. L., Dixon, P. H., Fox, J. W., Hong, S. E., Kinton, L., Sisodiya, S. M., et al. (2001). Mutations in the X-linked filamin 1 gene cause periventricular nodular heterotopia in males as well as in females. Hum. Mol. Genet. 10, 1775-1783. doi: 10.1093/hmg/10.17.1775

Sheen, V. L., Feng, Y., Graham, D., Takafuta, T., Shapiro, S. S., and Walsh, C. A. (2002). Filamin A and Filamin B are co-expressed within neurons during periods of neuronal migration and can physically interact. Hum. Mol. Genet. 11, 2845-2854. doi: $10.1093 / \mathrm{hmg} / 11.23 .2845$

Sheen, V. L., Ganesh, V. S., Topcu, M., Sebire, G., Bodell, A., Hill, R. S., et al. (2004). Mutations in ARFGEF2 implicate vesicle trafficking in neural progenitor proliferation and migration in the human cerebral cortex. Nat. Genet. 36, 69-76. doi: $10.1038 / \mathrm{ng} 1276$

Sheen, V. L., Jansen, A., Chen, M. H., Parrini, E., Morgan, T., Ravenscroft, R., et al. (2005). Filamin a mutations cause periventricular heterotopia with EhlersDanlos syndrome. Neurology 64, 254-262. doi: 10.1212/01.wnl.0000149512. 79621.df

Sheen, V. L., Topçu, M., Berkovic, S., Yalnizoglu, D., Blatt, I., Bodell, A., et al. (2003). Autosomal recessive form of periventricular heterotopia. Neurology 60, 1108-1112. doi: 10.1212/01.wnl.0000055898.00349.02

Shinohara, R., Thumkeo, D., Kamijo, H., Kaneko, N., Sawamoto, K., Watanabe, K., et al. (2012). A role for mDia, a Rho-regulated actin nucleator, in tangential migration of interneuron precursors. Nat. Neurosci. 15, 373-380, S1-S2. doi: $10.1038 / \mathrm{nn} .3020$

Solecki, D. J., Trivedi, N., Govek, E. E., Kerekes, R. A., Gleason, S. S., and Hatten, M. E. (2009). Myosin II motors and F-actin dynamics drive the coordinated movement of the centrosome and soma during CNS glialguided neuronal migration. Neuron 63, 63-80. doi: 10.1016/j.neuron.2009. 05.028

Sordella, R., Jiang, W., Chen, G. C., Curto, M., and Settleman, J. (2003). Modulation of Rho GTPase signaling regulates a switch between adipogenesis and myogenesis. Cell 113, 147-158. doi: 10.1016/s0092-8674(03) 00271-x

Soumiya, H., Fukumitsu, H., and Furukawa, S. (2009). Stem cell factor induces heterotopic accumulation of cells (heterotopia) in the mouse cerebral cortex. Biomed. Res. 30, 121-128. doi: 10.2220/biomedres.30.121

Symons, M., and Rusk, N. (2003). Control of vesicular trafficking by Rho GTPases. Curr. Biol. 13, R409-R418. doi: 10.1016/S0960-9822(03)00324-5

Taverna, E., Götz, M., and Huttner, W. B. (2014). The cell biology of neurogenesis: toward an understanding of the development and evolution of the neocortex. Annu. Rev. Cell Dev. Biol. 30, 465-502. doi: 10.1146/annurev-cellbio-101011155801

Théry, M., Racine, V., Pépin, A., Piel, M., Chen, Y., Sibarita, J. B., et al. (2005). The extracellular matrix guides the orientation of the cell division axis. Nat. Cell Biol. 7, 947-953. doi: 10.1038/ncb1307 
Thumkeo, D., Shinohara, R., Watanabe, K., Takebayashi, H., Toyoda, Y., Tohyama, K., et al. (2011). Deficiency of mDia, an actin nucleator, disrupts integrity of neuroepithelium and causes periventricular dysplasia. PLoS One 6:e25465. doi: 10.1371/journal.pone.0025465

Vidaki, M., Tivodar, S., Doulgeraki, K., Tybulewicz, V., Kessaris, N., Pachnis, V., et al. (2012). Rac1-dependent cell cycle exit of MGE precursors and GABAergic interneuron migration to the cortex. Cereb. Cortex 22, 680-692. doi: 10. 1093/cercor/bhr145

Wang, Z., Sandiford, S., Wu, C., and Li, S. S. (2009). Numb regulates cell-cell adhesion and polarity in response to tyrosine kinase signalling. EMBO J. 28, 2360-2373. doi: 10.1038/emboj.2009.190

Witte, H., and Bradke, F. (2008). The role of the cytoskeleton during neuronal polarization. Curr. Opin. Neurobiol. 18, 479-487. doi: 10.1016/j.conb.2008. 09.019

Woodhead, G. J., Mutch, C. A., Olson, E. C., and Chenn, A. (2006). Cellautonomous beta-catenin signaling regulates cortical precursor proliferation. J. Neurosci. 26, 12620-12630. doi: 10.1523/jneurosci.3180-06.2006

Yamana, N., Arakawa, Y., Nishino, T., Kurokawa, K., Tanji, M., Itoh, R. E., et al. (2006). The Rho-mDial pathway regulates cell polarity and focal adhesion turnover in migrating cells through mobilizing Apc and c-Src. Mol. Cell Biol. 26, 6844-6858. doi: $10.1128 / \mathrm{mcb} .00283-06$

Yang, B., Radel, C., Hughes, D., Kelemen, S., and Rizzo, V. (2011). p190 RhoGTPase-activating protein links the betal integrin/caveolin-1 mechanosignaling complex to RhoA and actin remodeling. Arterioscler. Thromb. Vasc. Biol. 31, 376-383. doi: 10.1161/ATVBAHA.110.217794

Yang, T., Sun, Y., Zhang, F., Zhu, Y., Shi, L., Li, H., et al. (2012). POSH localizes activated Rac1 to control the formation of cytoplasmic dilation of the leading process and neuronal migration. Cell Rep. 2, 640-651. doi: 10.1016/j.celrep. 2012.08.007
Yasuda, S., Oceguera-Yanez, F., Kato, T., Okamoto, M., Yonemura, S., Terada, Y., et al. (2004). Cdc42 and $\mathrm{mDia} 3$ regulate microtubule attachment to kinetochores. Nature 428, 767-771. doi: 10.1038/nature02452

Zhang, J., Neal, J., Lian, G., Hu, J., Lu, J., and Sheen, V. (2013). Filamin A regulates neuronal migration through brefeldin A-inhibited guanine exchange factor 2-dependent Arf1 activation. J. Neurosci. 33, 15735-15746. doi: 10 1523/JNEUROSCI.1939-13.2013

Zhang, J., Neal, J., Lian, G., Shi, B., Ferland, R. J., and Sheen, V. (2012). Brefeldin A-inhibited guanine exchange factor 2 regulates filamin A phosphorylation and neuronal migration. J. Neurosci. 32, 12619-12629. doi: 10.1523/JNEUROSCI. 1063-12.2012

Zhang, Y., Wang, F., Niu, Y., Liu, H. L., Rui, R., Cui, X. S., et al. (2015). Formin mDia1, a downstream molecule of FMNL1, regulates Profilin1 for actin assembly and spindle organization during mouse oocyte meiosis. Biochim. Biophys. Acta 1853, 317-327. doi: 10.1016/j.bbamcr.2014.11.005

Zhou, F., Leder, P., Zuniga, A., and Dettenhofer, M. (2009). Formin 1 disruption confers oligodactylism and alters Bmp signaling. Hum. Mol. Genet. 18, 2472-2482. doi: 10.1093/hmg/ddp185

Conflict of Interest Statement: The authors declare that the research was conducted in the absence of any commercial or financial relationships that could be construed as a potential conflict of interest.

Copyright (c) 2015 Lian and Sheen. This is an open-access article distributed under the terms of the Creative Commons Attribution License (CC BY). The use, distribution and reproduction in other forums is permitted, provided the original author(s) or licensor are credited and that the original publication in this journal is cited, in accordance with accepted academic practice. No use, distribution or reproduction is permitted which does not comply with these terms. 